\title{
ANALYSIS OF THE SIALIC ACID-BINDING ACTIVITY OF TRANSMISSIBLE GASTROENTERITIS VIRUS
}

\author{
B. Schultze, ${ }^{1}$ L. Enjuanes, ${ }^{2}$ and G. Herrler ${ }^{1}$ \\ ${ }^{1}$ Institut für Virologie \\ Philipps-Universität Marburg \\ Marburg, Germany \\ ${ }^{2}$ Centro De Biologia Molecular \\ CSIC Universidad Autonoma \\ Madrid, Spain
}

\begin{abstract}
Porcine transmissible gastroenteritis virus (TGEV) has been shown to agglutinate erythrocytes using $\alpha 2,3-$ linked sialic acid on the cell surface as binding site. The hemagglutinating activity requires the pretreament of virus with neuraminidase. We obtained evidence that TGEV recognizes not only $\mathrm{N}$-acetylneuraminic acid but also $\mathrm{N}$-glycoloylneuraminic acid, a sialic acid present on many porcine cells.
\end{abstract}

\section{INTRODUCTION}

Several coronaviruses are known to be potent hemagglutinating agents: bovine coronavirus (BCV), porcine hemagglutinating encephalomyelitis virus (HEV), human coronavirus OC-43 and some murine coronaviruses ${ }^{1}$. Each of these viruses possess two surface glycoproteins. The $\mathrm{S}$ protein is a hemagglutinin and interacts with cellular receptors. It shows fusion activity and induces neutralizing antibodies. The HE-protein is an acetylesterase and functions as receptor-destroying enzyme. Like the S protein, the HE protein is a hemagglutinin and induces neutralizing antibodies. Other coronaviruses, e.g. transmissible gastroenteritis virus (TGEV) and infectious bronchitis virus (IBV) show no or only weak hemagglutinating activity ${ }^{2}$. These viruses possess the S-protein, but they are devoid of a receptor-destroying enzyme. It has been shown that the hemagglutinating activity of IBV and TGEV requires the pretreament of virus with neuraminidase indicating that inhibitors on the virion surface have to be inactivated in order to induce the HA-activity of these viruses $^{3}$. The reason for the inhibitory effect of the surface-bound sialic acid on TGEV and IBV is that the virus recognizes a similar or identical sialic acid as receptor determinant. 
When sialic acid is removed from the surface of erythrocytes the virus can no longer agglutinate these cells. Erythrocytes which are resialylated and possess $\alpha 2,3$-linked N-acetylneuraminic acid on their surface are agglutinated by TGEV but to a lower extent than untreated erythrocytes. We were interested to find out whether sialic acids other than $\mathrm{N}$-acetylneuraminic acid are recognized by TGEV. Therefore, we tested agglutination of erythrocytes from different species.

\section{MATERIALS AND METHODS}

Virus. The Purdue strain of TGEV was propagated in LLC-PK1 cells.

Neuraminidase treatment of virus. TGEV was harvested from the supernatant of infected LLC-PK1 cells $48 \mathrm{~h}$ post-infection. After clarification of the medium by low-speed centrifugation $(2000 \mathrm{xg}, 10 \mathrm{~min})$, virus was pelleted by ultracentrifugation for $90 \mathrm{~min}$ at $54,000 \mathrm{xg}$. Virus was resuspended in PBS and incubated with neuraminidase from Vibrio cholerae (VCNA $500 \mathrm{mU} / \mathrm{ml}$ ) at $37^{\circ} \mathrm{C}$ for $30 \mathrm{~min}$. Following sedimentation of the virus by ultracentrifugation for $30 \mathrm{~min}$ at $100,000 \mathrm{xg}$, the virus was resuspended in PBS and used for hemagglutination assays.

Hemagglutination assay. Hemagglutinating activity was determined according to published procedures ${ }^{4}$. The hemagglutination titer (HA-titer) indicates the reciprocal value of the maximum dilution that caused complete agglutination.

Resialylation of erythrocytes. A $10 \%$ suspension of chicken erythrocytes was incubated with neuraminidase from Vibrio cholerae $(20 \mathrm{mU} / \mathrm{ml})$ for $30 \mathrm{~min}$ at $37^{\circ} \mathrm{C}$. Asialo cells were washed and suspended in PBS to a final concentration of $20 \%$ in a total volume of $200 \mu \mathrm{l}$. Resialylation was accomplished by incubation with $\alpha 2,3$ sialyltransferase $(5,2 \mathrm{mU})$ and $400 \mathrm{nmol}$ of CMP-activated N-acetylneuraminic acid (Neu5Ac) or $200 \mathrm{nmol}$ of activated $\mathrm{N}$-glycoloylneuraminic acid (Neu5Gc). After $2 \mathrm{hr}$ at $37^{\circ} \mathrm{C}$, cells were washed and used as a $1 \%$ suspension in a hemagglutination assay.

\section{RESULTS}

\section{Agglutination of Erythrocytes from Different Species by Neuraminidase-Treated TGEV}

Porcine transmissible gastroenteritis virus (TGEV) has been shown to agglutinate erythrocytes using $\alpha 2,3$-linked sialic acid on the cell surface as binding sites. The hemagglutinating activity requires the pretreatment of virus with neuraminidase ${ }^{3}$. We tested the hemagglutinating activity of TGEV with erythrocytes from several species which differ in type and amount of sialic acid on their surface. We used erythrocytes from chicken, one-day-old chicken, pig and cow in an agglutination assay with either untreated TGEV or neuraminidase-treated virus (Table 1). After pretreatment with neuraminidase TGEV was able to agglutinate erythrocytes from each of these species. In the case of bovine erythrocytes no pretreatment with neuraminidase was necessary to observe hemagglutination. Characteristic for bovine erythrocytes is that they possess a large amount $(91 \%)$ of N-glycoloylneuraminic acid (Neu5Gc) on their surface. This result was a hint that Neu5Gc may be a very efficient binding component for TGEV.

Sialic acids occur mainly in the terminal position of glycoproteins and gangliosides. They represent a large family of $\mathrm{N}$-and $\mathrm{O}$-substituted derivatives of neuraminic acid. $\mathrm{N}$-acetylneuraminic acid (Neu5Ac) and N-glycoloylneuraminic acid (Neu5Gc), respec- 
Table 1. Agglutination of erythrocytes by TGEV and neuraminidase-treated virus (TGEV-NA)

\begin{tabular}{lcc}
\hline & \multicolumn{2}{c}{ HA titer (HA units/ml) } \\
\cline { 2 - 3 } Erythrocytes & TGEV & TGEV-NA \\
\hline Chicken, adult & $<2$ & 1536 \\
Chicken, 1-day-old & $<2$ & 64 \\
Pig & $<2$ & 2048 \\
Cow & 32 & 768 \\
\hline
\end{tabular}

tively, are the two most frequently occuring sialic acid species. Their structure is shown in Fig.1.

\section{TGEV Binding to N-glycoloylneuraminic Acid on Erythrocytes}

Based on the findings with bovine erythrocytes, we analyzed whether TGEV was able to recognize $\mathrm{N}$-glycoloylneuraminic acid on erythrocytes more efficiently than $\mathrm{N}$-acetylneuraminic acid. Asialo cells obtained by treatment with neuraminidase from Vibrio cholerae were resialylated with either Neu5Ac or Neu5Gc in an $\alpha 2,3$-linkage. We compared the binding characteristics of neuraminidase-treated TGEV with two influenza viruses, fowl plague virus (FPV) and WSN strain for which the receptor determinant is already known, Neu5Ac, (Table 2). Erythrocytes resialylated with $\mathrm{N}$-acetylneuraminic acid were agglutinated efficiently by FPV and WSN, while the hemagglutinating acitivity observed with TGEV was very low. Among the two influenza viruses only FPV was able to recognize $\mathrm{N}$-glycoloylneuraminic acid. TGEV agglutinated red blood cells containing N-glycoloylneuraminic acid very efficiently. This result indicates that the preferred binding component of TGEV on erythrocytes is N-glycoloylneuraminic acid.

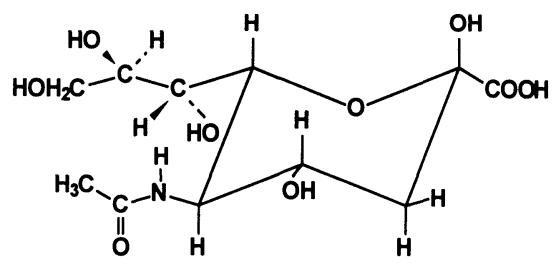

$\mathrm{N}$-acetylneuraminic acid

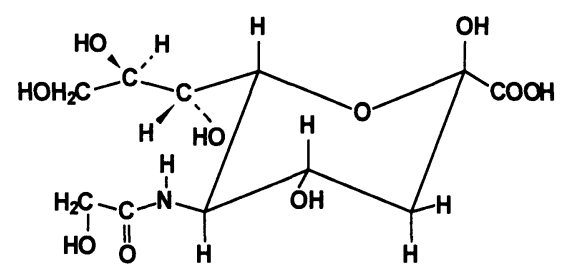

N-glycoloylneuraminic acid

Figure 1. Structure of N-acetylneuramınıc acıd (Neu5Ac) and N-glycoloylneuramınıc acid (Neu5Gc) 
Table 2. Restoration of receptors for neuraminidase-treated TGEV

(TGEV-NA) by resialylation of asialo-erythrocytes

\begin{tabular}{lccc}
\hline & \multicolumn{3}{c}{ HA titer (HA units/ml) } \\
\cline { 2 - 4 } Erythrocytes & TGEV-NA & FPV & WSN \\
\hline Control & 256 & 256 & 512 \\
Asialo & $<2$ & $<2$ & $<2$ \\
Resialylated & & & \\
Neu5Ac & 4 & 256 & 256 \\
Neu5Gc & 512 & 128 & $<2$ \\
\hline
\end{tabular}

\section{DISCUSSION}

Among coronaviruses there have now been identified several potent hemagglutinating agents Members of the BCV serogroup (BCV, HCV-OC43, HEV) recognize N-acetyl9-O-acetylneuraminic acid as receptor determinant, whereas IBV and TGEV bind to $\mathrm{N}$-acetylneuramınıc acıd and N-glycoloylneuramınic acid, respectıvely They differ not only in the type of sialic acid they recognize but also in the presence or absence of a receptor-destroying enzyme on the virus particle Viruses that use sialic acid for attachment to cells have to remove this common sugar from glycoproteins and glycolipıds that might act as inhıbitors and prevent binding of virus to the target cell In the case of BCV the acetylesterase-activity is responsible for the lack of N-acetyl-9-O-acetylneuraminic acid from potential inhibitors IBV and TGEV are devold of a receptor-destroying enzyme Therefore, the binding site for sialic acid is occupied by sialic acid-containing proteins Inactivation of these inhibitors by treatment with neuraminidase results in a binding activity to sialic acid The importance of the sialic acid-binding activity is not yet known

\section{REFERENCES}

1 Spaan W, Cavanagh D and Horzınek M C Coronavıruses structure and genome expression J Gen Virol 1988, 69 2939-2952

2 Schultze B, Cavanagh D and Herrler G Neuramınıdase treatment of avian infectious bronchitıs coronavirus reveals a hemagglutınatıng acitıvity that is dependent on sialic acid-containıng receptors on erythrocytes Virology 1992, 189 792-794

3 Schultze B , Enjuanes L, Cavanagh D and Herrler G N-acetylneuraminic acid plays a critıcal role for the hemagglutınatıng activity of avian infectıous bronchitıs virus and porcine transmissible gastroenteritıs virus Adv Exp Med Biol 1993, 342 305-310

4 Schultze B , Gross H -J , Brossmer R, Klenk, H -D and Herrler G Hemagglutınatıng encephalomyelıtıs virus attaches to $\mathrm{N}$-acetyl-9-O-acetylneuraminic acid-containıng receptors on erythrocytes comparison with bovine coronavirus and influenza C virus Virus Res 1990, 16 185-194 